\title{
IDENTIFICATION OF A SINGLE BASE POLYMORPHISM IN INTRON 2 OF THE c-fos GENE AND ITS DETECTION BY MISMATCHED PCR-RFLP
}

\author{
Kouzin Kamino, Tetsuro Miki, and Toshio Ogihara \\ Department of Geriatric Medicine, Osaka University Medical School, \\ 2-2 Yamadaoka, Suita, Osaka 565, Japan
}

A $\mathrm{T} \rightarrow \mathrm{C}$ transition in intron 2 of the c-fos gene was identified by sequencing analysis (Fig. 1). A simple method to detect this polymorphism was developed by mismatched PCR-RFLP. Allele frequency of this polymorphism was determined in the Japanese and in the Caucasian, separately. RFLP

Key Words Alzheimer's disease, c-fos, polymorphism, mismatched PCR-

Primer sequences for mismatched PCR.

FOS3-5: 5'-CAGACACTTTTACTGAATGTCG-3'

FOS3-3K: 5'-TCTTCTTCTGGAGATACCTAG-3'

This primer has a single base mismatch (underlined) which creates a detectable StyI site for allele b (CCTAGG), but not for allele a (TCTAGG) (Straaten et al., 1983). PCR amplification followed by digestion with StyI shows 62 bp for allele a, two bands of $41 \mathrm{bp}$ and $21 \mathrm{bp}$ for allele b (Fig. 2). These products can be analyzed by $20 \%$ polyacrylamide gel $(29: 1)$.

Allele frequency. Determined by analysis of 51 CEPH parents: $a: 0.94 ; b: 0.06$. Observed heterozygosity was 0.08 . Allele frequency was also analyzed in 20 unrelated Japanese: a: $0.92 ; b: 0.08$, observed heterozygosity: 0.15 .

Mendelian inheritance. Mendelian inheritance was demonstrated in two threegeneration and one two-generation families.

PCR conditions. PCR was performed in $20 \mu \mathrm{l}$ containing $100 \mathrm{ng}$ DNA, 1.5 $\mathrm{mM}$ of each primer, $150 \mu \mathrm{M} \mathrm{dNTP}, 1 \%$ formamide, $2 \mu 110 \times$ buffer $\left(1.5 \mathrm{mM} \mathrm{MgCl}_{2}\right)$ and $1 \mathrm{U}$ Taq polymerase (Perkin-Elmer) for 35 cycles as follows: $94^{\circ} \mathrm{C}$ for $45 \mathrm{sec}$, $60^{\circ} \mathrm{C}$ for $30 \mathrm{sec}, 72^{\circ} \mathrm{C}$ for $45 \mathrm{sec}$ with additional $1 \mathrm{sec}$ in each cycle.

Comments. The c-fos gene was evaluated in 4 patients of 4 independent families of early-onset Alzheimer's disease. This polymorphism was not co-transmitted

Received August 15, 1994; Revised version accepted September 21, 1994. 


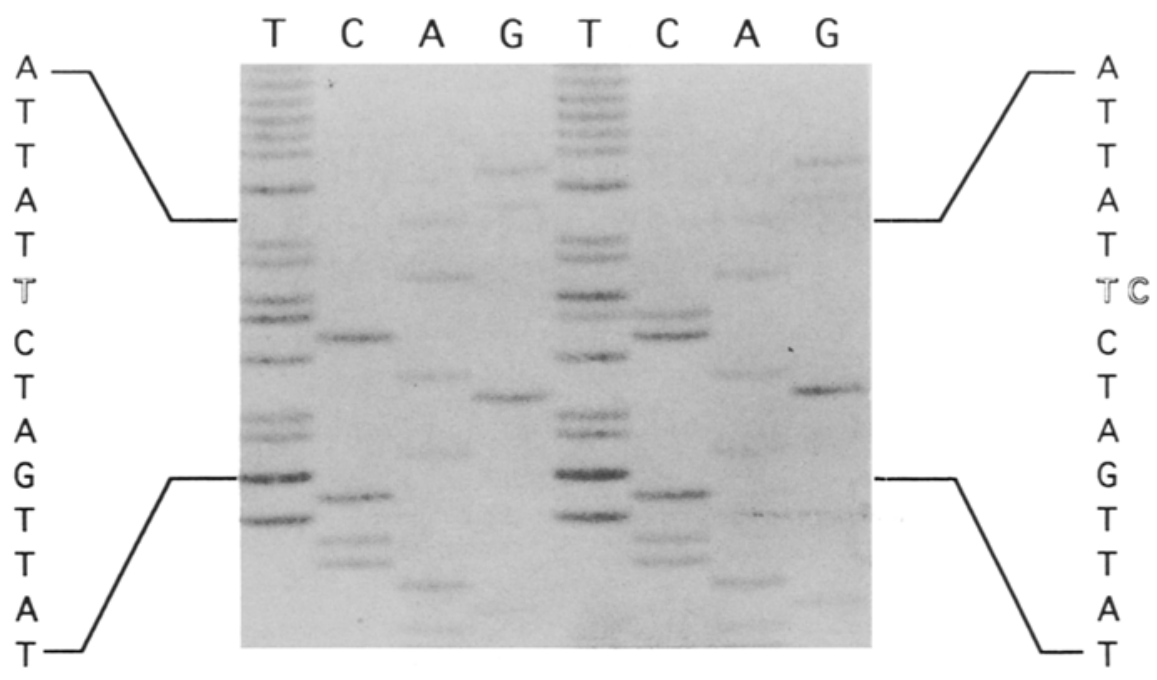

Fig. 1. Direct sequencing of the exon 3-intron 2 boundary of the c-fos gene. ATTAT T/C CTAG is the sequence of intron 2 and TTAT is that of exon 3.

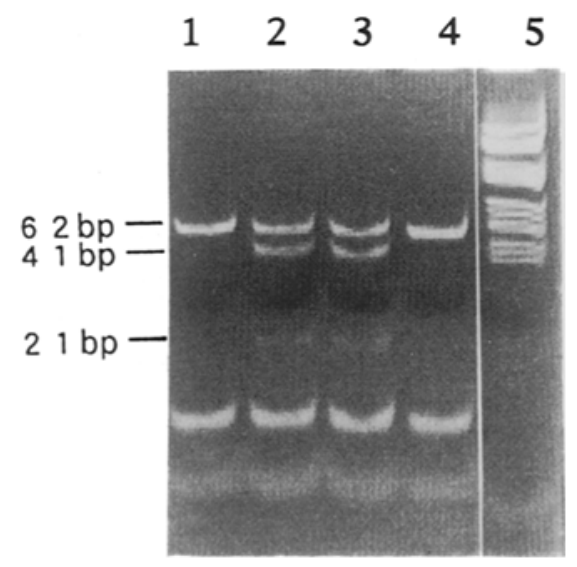

Fig. 2. Detection of a single hase polymorphism by mismatched PCR-RFLP. Homozygotes of allele a (line 1 and 4 ), and heterozygotes of allele a and b (lane 2 and 3) are shown. Lane 5 is MW marker (marker V, Boehringer-Mannheim).

with the onset of the disease. No other base changes were found in the exons and the exon-intron boundaries of the c-fos gene.

Acknowledgments This work was supported by the Grant-in-Aid for Scientific Research on Priority Areas, No. 04268102, Ministry of Education, Science and Culture of Japan.

\section{References}

van Straaten F, Muller R, Curran T, Van Beveren C, Verma IM (1983): Complete nucleotide sequence of a human c-one gene: Deduced amino acid sequence of the human c-fos protein. Proc Natl Acad Sci USA 80: 3183-3187 